\title{
Legal Reconstitution of Remedies for Damage Caused by Genetic Pollution
}

\author{
Chunyi Liu \\ China University of Political Science and Law, Beijing, China \\ Email:90liuchunyi@163.com
}

How to cite this paper: Liu, C. Y. (2021). Legal Reconstitution of Remedies for Damage Caused by Genetic Pollution. Open Journal of Social Sciences, 9, 451-467.

https://doi.org/10.4236/jss.2021.92029

Received: January 27, 2021

Accepted: February 23, 2021

Published: February 26, 2021

Copyright (c) 2021 by author(s) and Scientific Research Publishing Inc. This work is licensed under the Creative Commons Attribution International License (CC BY 4.0).

http://creativecommons.org/licenses/by/4.0/ (c) (i) Open Access

\begin{abstract}
Damage caused by genetic pollution is a new type of damage. At present, there are problems with the existing legal remedies for damage caused by genetic pollution. The purpose of this research is to explore the problems of the legal remedies for damage caused by genetic pollution, and discuss how to solve these problems by means of reconstitute the law. Doctrinal legal research methodology and Comparative legal research methodology is the main methodology in this research. Through discussing the logic of the relevant rules and comparing analysis of legal remedies under different countries, this research expounds the existing problems of the current legal remedies from three aspects and puts forward corresponding countermeasures. From the perspective of interpretation and application of relevant norms, based on the existing norms, there is an improper connection between the basic norms and the norms related to liabilities, which leads to ambiguities in the application of liability clauses. Therefore, relevant norms should be further explained or revised. Specifically, genetic pollution can be classified, and link with different forms of liability through legal interpretation. In legal practice, a single remedy mechanism based on civil liability is contrary to the complexity of genetic pollution. Introducing socialized remedies to construct multiple remedy mechanisms is a more reasonable path. The legal form based on administrative regulations and departmental rules also makes the legislation scattered and uncoordinated and lacks scientific and professionalism. Comprehensive and specialized legislation should be formulated to enhance the scientific and professional nature of the legislation.
\end{abstract}

\section{Keywords}

Genetic Pollution, Legal Remedy, Damage, Civil Liability

\section{Introduction}

Kariyawasam Kanchana provides a definition in a research as: "An irreversible 
or uncontrollable escape of genes from a GM crop to neighbouring plants of the same species, wild or domestic which caused negatively impact on agriculture, biodiversity, human health" (Kariyawasam, 2010). This definition restricts the medium that may cause damage to crops. Obviously, the scope of this definition is too narrow. Wang Kang believes that the definition of damage caused by genetic pollution is: "Due to improper application of genetic modification technology, artificially modified genes drift to the gene pool of native species, and accidental mixing of genetically modified organisms and their products into traditional organisms, causing unexpected changes in the natural ecosystem at the genetic level" (Wang, 2016). This definition defines damage as a change. Obviously this is inaccurate, because changes may include positive changes and negative changes. Miles L. S. also pointed this out: "Damage' is a political value judgment, which does not present objective facts. So we should distinguish between the two concepts of damage and change" (Miles et al. 2019). The FAO believes that damage caused by genetic pollution should refer to the uncontrolled spread of genetically modified genes into the genomes of organisms where such genes do not exist in the natural state, resulting in negative effects. This definition is concise and accurate, but it does not specify the damage object (Zaid et al., 2001). The Secretariat of the Convention on Biological Diversity pointed out that the damage caused by genetic pollution is "a major adverse effect on the ecological environment and human health caused by living organisms with a new combination of genetic materials obtained through modern biotechnology" (Tapper et al., 2003). This research believes that the most accurate definition of damage caused by genetic pollution should be: "the infringement of multiple rights and interests such as personal, property and environment caused by the application of genetically modified."

The damage caused by genetic pollution is the migration of genetic material containing genetically modified factors from one organism to another. In China, there are only two administrative regulations for the damage caused by genetic pollution infringement, which are transferred to the "Civil Code" tort liability for remedy. Existing legislation cannot guarantee effective remedies for damage caused by genetic pollution, whether based on legal logic or judicial practice. This article intends to examine and reflect on the remedy mechanism of damage caused by genetic pollution from three aspects. First of all, from the logic of the relevant regulations, there is an improper connection between remedy norms and basic norms. The general liability clauses are insufficient in identifying genetic pollution. So it is necessary to redefine damage caused by genetic pollution and its liability at the normative level, in addition, enhance the recognition of liability clauses against genetic pollution is important because of the diversity of genetic pollution. Secondly, from the legal practice of damage caused by genetic pollution: the remedy mechanism based on civil liability must be optimized. There is an ambiguity between the litigation system and the damage facts in the remedy mechanism based on civil liability. There is a conflict between sociality of genetic pollution and the individuality deviation of the civil liability. So the 
civil liability is difficult to deal with genetic pollution with huge damage. It is a better choice to establish an insurance system and a public compensation fund for damage. Thirdly, On the legislative model, existing legislation lack of coordination. The legal rank of relevant legislation is not high. To deal with this situation, the best way is to formulate comprehensive special legislation to ensure that the legislation is scientific and professional.

\section{Literature Review}

Regarding the legal remedies for damage caused by genetic pollution, many scholars have raised the issue of the existence mechanism and put forward suggestions for legal reconstitution.

Que Zhanwen believes that according to the dangerous attributes of genetically modified organisms and the stage of genetic pollution caused by genetically modified organisms, the damage caused by genetic pollution can be distinguished from damage caused by genetically modified organisms in the experimental stage and damage caused by genetically modified organisms that have been licensed for marketing. The former includes damages caused by genetically modified organisms that are in the stage of laboratory research or field trials, and the common form of the latter is damage that occurs during the production process after the genetically modified organisms are licensed for marketing. In terms of the risk of genetic pollution in the experimental stage and the damage compensation function of the tort liability law, the damage in the experimental stage is a special tort, and no-fault liability applies. After the genetically modified organisms are approved for marketing, if the damage exceeds the tolerance limit, the victim can request to eliminate the damage or eliminate the danger; if it causes damage to the real property right holder, the victim can also request compensation for damage. If the nuisance does not exceed the tolerance limit, the victim can exercise the right to claim compensation (Que, 2015). Wang Kang also expressed his views on the relief of genetic pollution damage. The "Regulations on the Safety Management of Agricultural Genetically Modified Organisms" have only simple clauses that the tort law should be applied. One problem is that as far as the current tort law is concerned, private law remedies can only be provided for damages to the "civil rights" of the victims caused by genetic pollution, and there is nothing to do with damages other than "civil rights" (Wang, 2016). Tort law is facing the advent of a risky society, and the remedy mechanism for damage should be adjusted according to this change.

Xin Shuai pointed out that the remedies of civil liability in the damage caused by genetically modified pollution are naturally insufficient. The victims have natural disadvantages in presenting evidence and often fail to provide evidence. The civil liability is designed based on the protection of the individual's civil interests, and cannot fully cover all types of damage caused by genetic pollution (Xin, 2015). Du Zhenyuan pointed out that civil liability mainly protects personal rights and property rights, and lacks attention to environmental rights. Therefore, when making GMO damage compensation legislation, the content of 
environmental rights protection should be added. While formulating the genetically modified organism safety law, China must increase research on the genetically modified organism damage compensation system and issue a special genetically modified organism damage compensation law as soon as possible to effectively regulate genetically modified technology and its research and development activities. my country should clearly adopt the financial guarantee rules required by the "Nagoya-Kuala Lumpur Supplementary Protocol" in its legislation to ensure that the injured party can receive compensation in a timely and adequate manner. Financial guarantee refers to the use of government credit to provide guarantees for high-risk investment activities undertaken by enterprises, institutions or individuals, and promise to bear the responsibility for the failure of investment activities. After the financial guarantee rules are clarified, the government promises to bear the liability of the operators to compensate, the enterprises that carry out activities related to genetically modified technology or genetically modified organisms should provide certain funds for compensation for victims of genetically modified organism damage ( $\mathrm{Du}, 2014)$. Lv meng xing regards the damage caused by genetic pollution as a kind of environmental damage. For environmental damage, it is obviously a better choice to establish a diversified remedy mechanism than civil liability with a single function. Legislators should give full consideration to the uncertainty and diversity of environmental public interests, establish multiple protection mechanisms at the level of institutional design, and form an institutional system in which multiple subjects participate together and multiple paths coexist, which is conducive to fully mobilizing all subjects to participate in the environment The enthusiasm of governance, give full play to the joint force of the system (Lv, 2021).

As can be seen from the foregoing, scholars' views can be divided into two categories. One is to start from the civil liability itself, reinterpret the relevant regulations, and seek a better application of liability. The other is to seek a better remedy mechanism outside of civil liability. This research believes that these two aspects are not contradictory. However, some previous scholars' opinions are insufficient and worthy of refinement. This research has some new thought into these two aspects. And trying to find the best path of legal reconstitution of remedies for damage caused by genetic pollution.

\section{Redefinition of the Logic of Norm Application}

\subsection{Existing Regulations Are Insufficient to Explain the Damage Caused by Genetic Pollution}

As far as the current legislation is concerned, the remedy of the damage caused by genetic pollution is mainly relying on the civil liability, which has its special logical structure. This remedy pattern is realized through the Tort Law, and the basic model of the relationship is a certain basic right stipulated by law is violated, resulting in the right to claim the liability (Wang, 2009).

The right to claim the liability in the norms is not systematized, but should be 
scattered throughout multiple legal departments, so there are generally one or several cohesive norms between the basic right and the right to claim the liability. For example, Article 48 of "China's consumer rights and interests protection law" stipulates that operators who provide goods or services that cause harm to consumers shall bear tort liability. Another example is "Environmental Protection Law of the People's Republic of China", "Food Safety Law of the People's Republic of China", and "Securities Law of the People's Republic of China" These legislations also have such cohesive provisions. Legislation related to damage caused by genetic pollution is no exception. The "Regulation on Administration of Safety of Agricultural Genetically Modified Organisms" and the "Management Rules on Genetic Engineering" both stipulate that damage caused by genetic pollution shall be liable for compensation in accordance with the law. However, the meaning of the term "in accordance with the law" used here is very vague. The question not stated in this article is: whether we claim Liability in accordance with "Environmental Protection Law of the People's Republic of China" or "China's consumer rights and interests protection law" and so on. There are multiple types of liability in the tort liability chapter of the Civil Code and it is not clear which type of liability should be linked to the damage caused by genetic pollution. The above-mentioned problems have not been clarified in existing legislation, which has created great obstacles to the application of relevant laws.

Article 1165 and Article 1166 of the Tort Liability of Civil Code stipulate the constituent elements of fault liability and strict liability respectively, and the core elements are "damage". However, neither existing norms nor theoretical doctrines can accurately define the scope of damage caused by genetic pollution. In the interpretation of damages in German Law and, there have been theories such as the "difference theory" which emphasizes value reduction, the "organization theory" which emphasizes tangible damage, and the "normative damage theory" which entrusts the judgment of damage to specific norms. In 1855, Mommsen first put forward the point of "difference theory" that the damage is the decrease in the total amount of the victim's property caused by the infringement accident, that is, the amount of the victim's property after the damage accident and the assumption of the damage The difference between the amount of property that should be under the condition that the accident does not occur, the former is the specific property status, and the latter is the assumed property status (Markesinis \& Unberath, 2002). After that, the concept of difference theory was accepted by scholars such as Windschiedo, Fischer, enneccerus, etc., and then became the mainstream theory. However, this doctrine only focuses on losses calculated based on market prices, and fails to take into account interests that do not have property value. In response to this shortcoming, the German scholar Altman put forward the "organization theory" that focuses on tangible damage. He believes that damage is often accompanied by deprivation, damage or bodily harm, and deprivation, damage or bodily harm of the components of the thing (Koch \& 
Koziol, 2002). According to the "organization theory", when the victim has no property difference loss or no specific personal or property damage, there is no damage. This will make the damage that should be remedied cannot be recognized, and it is contrary to legal principles. In this regard, scholars put forward the "normative damage theory". "Normative damage theory" means the grasp of damage is not only an observation of factual damage, but a determination based on the functions of relevant laws (von Bar et al., 2009). Chinese scholars have basically inherited or used the above three theories to explain the damage, such as "damage usually refers to the non-interest suffered by protected legal interests." and "damage is composed of two elements: the right is There is a loss in damage and interests" (Yang, 2014). None of the above three theories can provide a reasonable explanation for the property damage caused by genetic pollution. There are two reasons. First, the changes caused by genetic pollution are complex, and sometimes it is difficult to judge changes in their economic value. Sun Weilin found in her "Research on the Economic Impact of Commercialized Planting of Transgenic Insect-resistant Corn in my country": "The output value per unit area of transgenic insect-resistant corn planted in the four provinces of China in the past ten years has increased compared with non-transgenic corn" That is to say, the conversion of non-GMO varieties caused by genetic drifting into transgenic varieties may lead to an increase in yield. Under this circumstance, it is not easy to judge changes in economic value (Sun, 2011). The second is the diversity of genetic pollution infringement. The damage caused by genetic pollution has the obvious complexity of public law and private law, and the objects are diverse. In addition to the traditional legal benefits of personal and property, it also directly points to biological gene banks and ecosystems. The doctrine's explanation of damage is based on personal property rights, and there is a problem of insufficient explanatory power in the face of diversified damage caused by genetic pollution.

\subsection{Classification of Related Activities to Connect to Different Liability}

There are several domestic theories regarding the application of liability for damage caused by genetic pollution, and the representative ones are the "high-risk liability theory" and the "stage division theory". The theory of high-risk liability believes that the widespread use of genetically modified technology may bring unexpected high-risk, so it is also a high-risk operation, which should be included in the adjustment scope of high-risk liability. This explanation is a big improvement over the current crude norms, but it is still not enough to accurately cover the complex situation of genetic pollution infringement. The "stage division theory" advocates the distinction between behaviors that cause genetic pollution, and links to corresponding liability categories based on the characteristics of the behaviors. The stage at which genetic pollution occurs can be distinguished between genetic pollution caused by genetically modified organisms 
in the experimental stage and genetic pollution caused by genetically modified organisms that have been approved for marketing. The former shall be subject to the high-risk liability in tort law, and the latter shall be subject to the indispensable liability in Property Law.

The best way to deal with genetic pollution should be to clearly define the scope of genetic pollution in the norms, and classify them based on the risk of activities to connect to different types of liability. Specifically, genetically modified organisms have multiple attributes. Under different circumstances, they may be non-dangerous ordinary goods or dangerous pollutants. Activities related to genetically modified organisms may be beneficial economic activities. Necessary components may also constitute activities with a high risk of harm to the environment and human health. Therefore, it is necessary to make a classification based on the risk of genetically modified activities. Article 6 of the existing "Management Rules on Genetic Engineering" requires the classification of genetic engineering work to determine its risk, but the scope of application of this article is too narrow and can only be applied to genetic engineering work, and does not involve commercial application of genetic technology. The classification and evaluation system in the "Regulation on Administration of Safety of Agricultural Genetically Modified Organisms" has more reference significance. According to the degree of danger to humans, animals and plants, microorganisms and the ecological environment, the system divides agricultural genetically modified organisms into four levels: no danger, low danger, moderate danger, and high danger. The safety assessment of agricultural genetically modified organisms generally involves several stages of laboratory research, intermediate testing, environmental release, production testing and biosafety certificates. Those who produce, operate, or import agricultural genetically modified organisms also need to obtain production, operation or import licenses. At each stage, the applicant must submit information about the test situation, safety management and preventive measures to the competent authority, and the competent authority will organize the scientists to evaluate it.

To sum up, the current legislation classifies genetically modified organisms into four levels: non-hazardous, low-risk, middle-risk, and high-risk. However, there is currently no legislation linking this classification with the relief of damage. The author believes that damage caused by genetically modified activities with a high-risk can be included in the scope of dangerous liability through the interpretation $\mathrm{o}$, while for non-risky or less dangerous genetically modified activities Can be included in the scope of the general tort liability.

\section{Expansion of Remedy Mechanism of Damage Caused by Genetic Pollution}

\subsection{As a Remedy Pattern, Civil Liability Is Contrary to the Complexity of Genetic Pollution}

In practice, civil liability is realized through judicial procedures. There is a con- 
tradiction between the requirement of the burden of proof in the civil litigation and the complexity of genetic pollution. In the initiation stage of the litigation, in accordance with the provisions of my country's Civil Procedure Law, the plaintiff needs to have a clear defendant and at the same time prove that he has a direct interest in the case during the litigation stage, the plaintiff needs to bear a certain burden of proof. This requirement is actually not easy to achieve in genetic pollution cases. Genetic pollution is different from general tort cases. In general tort cases, the tort relationship is relatively simple. The perpetrator, the victim, and the fact of the damage are very clear. Relatively genetic pollution is very different. In this process, the victim's specific property may become a medium for the continued transmission of heterogeneous genes, turning the victim into a perpetrator. Therefore, it is practiced as a victim in genetic pollution infringement. It is difficult to collect and find direct evidence of facts related to damages, interests, etc. So it is not easy to initiate a civil remedy mechanism. In 2009, genetically modified pollution was detected in flax seeds exported from Canada to Europe, which prevented Canada from meeting the EU's new contract requirements for biosafety, severely affecting sales and triggering the collapse of the market. The GM flax pollution incident led to Canada The direct purchase price of linseed by farmers has plummeted, causing huge economic losses for Canadian farmers. Afterwards, most of the victims were unable to file a lawsuit in a Canadian court due to lack of evidence, highlighting the limitations of judicial procedures on this issue (Chen, 2015). In addition, a social survey on victims of genetic pollution damage in China also revealed this point (Liu, 2012). The survey designed a question that is if you have been harmed by environmental pollution, what kind of remedies would you take? The survey distributed more than 2000 questionnaires in Shandong and Jiangsu provinces and received 938 responses, of which only 159 people chose to go to court to prosecute. Most people choose other ways to solve. The statistics of the measures that victims will take in the face of environmental pollution are shown in Figure 1 .

From the figure, we can see that only $17 \%$ of all respondents are willing to defend their rights through litigation. The result of this investigation is a strong evidence of the limitations of the civil liability as a remedy mechanism.

There is a contradiction between the statute of limitations system and the time delay of genetic pollution. In most cases, the process of damage caused by genetic pollution manifests as progressive and latent damage. As mentioned above, genetic pollution is achieved through the mechanism of gene drifting. The foreign genes released by genetically modified organisms are often transmitted through water currents, air currents, animals, etc., and at the same time cause harmful effects through the mediation of seeds or pollen. This process usually requires a certain period of continuous accumulation to produce identifiable damage consequences. When the victim finds out, it is likely to have exceeded the statute of limitations so that civil law cannot be adopted. 


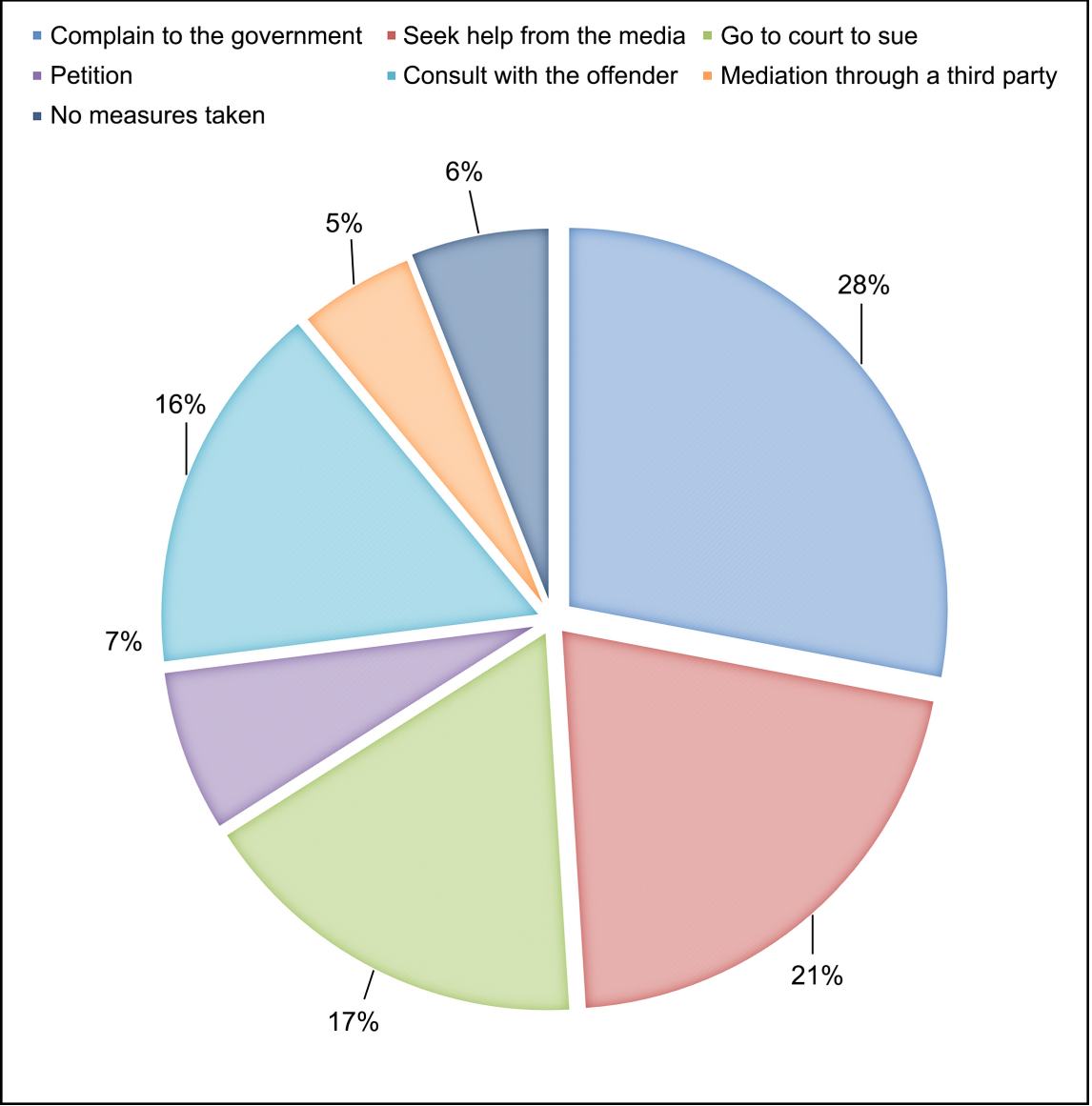

Figure 1. Percentage of various measures taken to face environmental pollution.

The civil liability is an individualized remedy mechanism, which implements the principle of "whoever infringes, who is responsible", and the responsible person is ultimately responsible for compensation. However, genetically modified organisms do not exist in isolation. It gene fragments can continuously enrich and accumulate in the ecosystem and food chain in this way. It is very likely to cause serious damage that the perpetrators of genetic pollution often do not have the ability to compensate. The "Starlink Corn Incident" in the United States is a typical example. "Starlink" genetically modified corn is a crop developed by a US company for animal feed. It was not intended for human consumption. However, in 2000, the genetically modified ingredients of "Starlink" corn were detected in foods for human consumption in the market. There are also consumers. It is claimed that eating genetically modified ingredients containing "Starlink" corn has caused allergies and diarrhea. After testing by the laboratory of the US Department of Agriculture, about 10\% of the corn harvested in the United States that year was contaminated by "Starlink" corn. Three years later, it can still be found in $1 \%$ of the national corn samples (Chen, 2007). The economic loss caused by the entire incident is estimated to be one billion U.S. dollars. The impact on the environment is immeasurable. On the one hand, the type of large-scale infringement has characteristics that the traditional infringe- 
ment does not have. So the remedy of the damage facts must break through the original procedures and establish an appropriate damage remedy method to achieve the best effect. On the other hand, it is obviously difficult to realize such a huge loss if a civil remedy mechanism is adopted to allow the individual responsible to bear it. The existing remedy mechanism must be revised.

The civil liability is rooted in the civil law department that adjusts the relationship between equal subjects, and aims to perform the function of maintaining fairness and filling the damage for individuals. Activities related to genetic pollution have a strong sociality. There is an irreconcilable conflict between individual-oriented norms and highly social activities. The famous British sociologist Anthony Giddens regards genetic pollution and other infringements related to new technologies as a social risk. He believes that the great productivity development brought about by the Industrial Revolution has caused the rapid expansion of social wealth, and technological progress is bringing material prosperity. At the same time, it also brings risk to the society, which is more difficult to predict and control. At the same time, he also pointed out that bearing these risks is a necessary price for the continuous progress of human civilization (Lin, 2014). According to Anthony's point of view, damaged caused by genetic pollution are essentially different from traditional torts. Damaged caused by genetic pollution are generated during the development and utilization of genetically modified technologies. They are different from general torts that suffer from double negative evaluations in terms of morality and law. Infringement itself is a social risk brought about by technological progress, and it is a social cost for human society to continuously carry out technological innovation and achieve civilized progress. It itself has certain value legitimacy. If all such infringements are entrusted to the civil remedy mechanism, and the responsible person is brought to bear the excessive amount of compensation by litigation, it will only greatly aggravate the cost and risk of technological innovation, and it will not be conducive to the progress and development of human society.

\subsection{Establish a Remedy Mechanism with Equal Emphasis on Socialized Remedy and Civil Liability}

As mentioned in the previous article, activities related to genetic pollution infringement have a certain sociality. Such activities involve the development and utilization of new technologies, which promote social progress and bring certain social risks. Genetic pollution caused by such activities It is precisely this kind of social risk. In order to cope with this risk, the legal system should be adjusted and innovated appropriately. Specifically, it is to shift from "individualization" to "individualization" and "socialization". The object of direct legal adjustment is no longer just individuals but also including society as a whole. To implement the remedy mechanism is to introduce a socialized remedy mechanism and build a remedy mechanism that emphasizes both socialized remedy and civil remedy.

Tort socialized remedy means that the damage caused by the tort damage is 
regarded as social damage, and the damage compensation system is highly designed through liability insurance, public compensation, etc., so that the majority of people in the society bear and digest such damage. Then damage compensation is no longer a mere burden on the infringer themselves (Zou, 2005). Judging from the current legislation available for reference, social remedies mainly include the damage insurance and the public compensation fund. Damage insurance refers to the type of insurance in which the insurer pays compensation to the third party according to the insurance contract when the insured should be liable for damages to the third party in accordance with the law. In terms of the function of the damage insurance, the insurance actually transfers the risk to the insured person, which greatly reduces the cost of the perpetrator in the case of genetic pollution. The insurance can also effectively supervise the responsible person to prevent risks through insurance contracts and minimize damage when an accident occurs. Therefore, it is very necessary to introduce a whole insurance system to deal with genetic pollution. From the perspective of comparative law, insurance is a relatively mature legal system in developed countries in Europe and America. "The United States' Comprehensive Environmental Response, Compensation and Liability Act" and "the Resource Conservation and Restoration Act", "Germany's Environmental Liability Act", "Sweden's Environmental Protection Act", "France's Environmental Act", and "Harmful Facilities Control Act" All clauses specifically provide for tort liability insurance (Zhou \& Yang, 2003). China currently only has provisions for specific matters in the "Marine Environmental Protection Law" and the "Regulations on Compulsory Motor Vehicle Traffic Accident Liability Insurance". In view of the harmfulness of genetic pollution, it is recommended to modify the "Regulation on Administration of Safety of Agricultural Genetically Modified Organisms" and "Management Rules on Genetic Engineering" to establish a damage insurance system sufficient to deal with genetic pollution.

Although the insurance system mentioned in the previous article can enhance the perpetrator's ability to compensate in genetic pollution tort cases to a certain extent, it is ultimately based on the free market to provide agreed compensation. In order to guarantee its own interests, insurance companies will set corresponding procedures and physical conditions for claims, so the coverage is limited, and the amount of insurance is also capped. At this time, the necessity of establishing a public compensation fund is highlighted.

The public compensation fund system is the last line of defense to maintain social stability and ensure fairness and justice in the field of infringement relief. Public compensation fund is a fund that provides compensation for damage caused by infringement. It is formed through various methods such as government taxes and fees, funds from potential polluting enterprises, financial appropriations and social raising (Jia, 2011). Unlike the insurance, which belongs to product of the market, the public compensation fund is established as a public welfare fund by the government. In genetic pollution, there are often situations 
where the causality cannot be confirmed, and there is a lack of facts or legal basis to initiate Judicial procedure. At the same time, this situation does not meet the conditions of compensation for the insurance. So the public compensation fund can make a difference to pay the victim. As early as the last century, the United States and Japan had legislated and established public compensation funds for certain damage. They respectively formulated the "Super Fund Law" and the "Public Hazard and Health Damage Compensation Law." The two laws authorize the government to raise funds through special appropriations, collection of special taxes, and acceptance of donations to achieve compensation for specific infringements, including compensation for "large-scale damage caused by dangerous substances." Obviously genetic pollution infringement, it is also included, so it is recommended that my country also set up a public compensation fund to protect the interests of the victims.

\section{Optimization of Legislation System for Damage Caused by Genetic Pollution}

\subsection{Existing Legislative Pattern Restricts the Implement of the Remedy Mechanism}

Generally speaking, legislation in a certain field can be divided into three types according to its legislative patterns: 1) Unified comprehensive legislative pattern, that is, a country formulates a unified basic law to adjust various relationships and activities in a certain field. For example, the "Genetic Engineering Law" enacted by Germany in 1990. 2) The single legislative pattern, which refers to the adjustment of activities for a certain element in a specific field by formulating separate regulations. It is a more micro legislative pattern than the first legislative pattern. This is the case in our country's legislation on genetic modification 3) Hybrid legislative pattern. The legislative pattern specifically refers to a pattern of legislation based on a specific field using a unified basic legislative model and a single law and regulation model. The mixed legislative pattern is the most common legislative pattern of in modern countries.

Regarding the legislation on damage caused by genetic pollution, China has actually pursued a single legislative pattern dividing agricultural genetic modification and genetic engineering into two areas for separate legislation. "Regulation on Administration of Safety of Agricultural Genetically Modified Organisms" and the "Management Rules on Genetic Engineering" are divided into separate regulations on genetic pollution caused by agricultural genetically modified organisms and genetic pollution caused by genetic engineering. However, this approach is not conducive to solving the problem of damage caused by genetically modified pollution. At present, the two main legislations, "Regulation on Administration of Safety of Agricultural Genetically Modified Organisms" and the "Management Rules on Genetic Engineering" lack coordination with each other, and there are cases where the same matters are repeatedly stipulated, which will lead to conflicts between regulations. The most obvious is the defini- 
tion of damage caused by genetic pollution in the two legislations. Article 52 of the "Regulation on Administration of Safety of Agricultural Genetically Modified Organisms" defines damage caused by genetic pollution as that animals, plants, microorganisms and their products that use genetically modified technology, these products have caused damage in the course of research, testing, processing, storage, transportation, sales, or import and export. Article 3 of the "Management Rules on Genetic Engineering" defines damage caused by genetic pollution as damage caused by the use of genetic engineering technology for experimental research, pilot testing, industrial production during the release or use of genetic engineering. As we can see, the "Management Rules on Genetic Engineering" has a broader definition, which actually includes the definition of the "Regulation on Administration of Safety of Agricultural Genetically Modified Organisms" on damage caused by genetic pollution, which will cause conflicts in the application of different norms.

In the current existing legislation, the "Regulation on Administration of Safety of Agricultural Genetically Modified Organisms" are administrative regulations, and the "Management Rules on Genetic Engineering" are departmental regulations. The levels of the two legislations are not high, which will directly affect the management of genetic technology and remedies for genetic pollution. The application of genetically modified technology is becoming more and more widespread. It is no longer limited to scientific experiments and crop cultivation, but gradually extends to all aspects of life. Therefore, if there is no high-level specific legislation, it means that matters related to genetically modify are blocked. In this case, matters relating to the genetic pollution are fragmented into many issues, and these issues are under the jurisdiction of different legal departments. It is obviously not conducive to the remedy of genetic pollution.

The existing legislation is not based on the scientific research about genetic technology. Damage caused by genetic pollution is closely related to the development and utilization of genetic technology and the management of genetically modified organisms. Therefore, scientific methods must be used to research and judge activities that cause genetic pollution to accurately incorporate the phenomenon of genetic pollution into the legal field.

However, the two legislative provisions of the "Genetic Engineering Safety Management Measures" and the "Regulations on the Safety Management of Agricultural Genetically Modified Organisms" are simple and inaccurate resulting in gaps in liabilities and management when applied. The most typical example is the definition of the targets of genetic pollution in the two legislations. The "Genetic Engineering Safety Management Measures" define the targets of the ecological environment and human health, while the "Regulations on the Safety Management of Agricultural Genetically Modified Organisms" do not specify genetically modified agricultural use. Objects infringed by genetic pollution caused by organisms. It is not difficult to see that the definitions of the infringement objects in the two legislations are relatively vague, and the final result is 
that it is difficult for victims to fully claim their rights in accordance with this rule in the application of the law. The existing legislation has deviations in the legislative view. The existing legislation simply transfers genetic pollution infringements to the "Civil Code" tort liability for solution, which is essentially equivalent to simply including genetic pollution infringements into the field of general tort liability, but genetic pollution infringements have their particularities It is not only to solve the problem of how to achieve adequate relief to the victims, but also to reduce risks and promote social progress. That is to say, the risk and benefit coordination legislative concept that the relevant legislation of genetic pollution tort should implement. The existing legislation does not reflect this, and it is difficult to promote social progress.

\subsection{Improvement Path of Remedies for Damage Caused by Genetic Pollution}

Many countries in the world have adopted a Unified comprehensive legislative pattern on matters related to genetically modified technology, especially in those countries where genetically modified technology is widely used. With the continuous deepening of research and development and application of genetically modified technology in my country, the need to learn from this legislative model is increasing. According to the data provided by the International Agricultural Biotechnology Application Service Organization in 2018, my country has become the world's top ten GM crops growing countries, and Brazil, Canada, and India have all implemented special legislation. In this regard, German legislation has important reference significance. Germany enacted the "Genetic Engineering Law" as early as 1990. This is a comprehensive and unified legislation that comprehensively establishes the use of genetically modified organisms, scientific research on genetically modified organisms, the release of genetically modified organisms, and the listing of genetically modified products, as well as damage caused by genetically modified organisms (Wang, 2010). The legal framework of damage and other related matters makes Germany lead the world in terms of genetic modification legislation.

In order to promote technological progress, reduce the social risks of technology, and balance the interests of all parties, it is very necessary to formulate a "Genetic Technology Law". Formulate Unified comprehensive legislation specifically regulating genetic pollution, the "Gene Technology Law." Special legislation must uniformly define various terms on the basis of scientific research and judgment, so as to avoid the occurrence of contradictions and duplications in the norms of multiple legislation. The remedy of genetic pollution is a holistic and comprehensive issue, which is closely related to the evaluation, development and production licenses of genetically modified organisms. Therefore, the evaluation, development and production licenses, data collection, compensation and other related issues of genetically modified organisms should be coordinated in a special legislation. At the same time, it will safeguard personal rights, protect the 
ecological environment, reduce technical risks, and promote Values such as social progress are incorporated into legislation to determine the order of these values in legislation on this basis, integrate the civil remedy mechanism and the socialized remedy mechanism to form a professional, comprehensive and scientific legislation.

The formulation of special legislation should take the form of law and raise the level of legislation. On the one hand, in practice, the public's perception of the law has an important influence on the effect of law enforcement. Elevating the legislative rank can enhance the authority of justice and law enforcement, increase society's awareness of related matters, effectively reduce the constraints of departmental interests in law enforcement, and fully guarantee the effect of law enforcement. On the other hand, raising the legislative level ensures the uniformity of the application of norms. Due to the wide range of applications of genetically modified technology, it is inevitable that it will have various relationships with other legislations such as the Food Safety Law, the Environmental Protection Law, the Tort Liability Section of the Civil Code, etc., or conflicts, or references. Therefore, Only by raising the level of legislation and clarifying the application of laws and regulations on various matters related to genetic modification can we handle the relationship with other legal departments.

\section{Conclusion}

The existing legal remedies for damaged caused by genetic pollution mainly rely on civil liability. Previous researches have pointed out that civil liability as a remedy mechanism has problems in the face of damage caused by genetic pollution. In response to these problems, previous scholars have proposed two paths to legal reconstitution. The first is to proceed from the relevant regulations on genetic pollution, carry out legal interpretation, classify the damage caused by genetic pollution, and apply different liabilities. The second is to build a diversified remedy mechanism beyond civil liability. The contribution of this research is to point out there were shortcomings of existing opinions and norms, and propose my own suggestions for improvement. Specifically, according to the legal interpretation, the functions of the genetic pollution damage remedy mechanism should be the following: one is that it should guarantee full compensation to the victims; the other is to reduce the risk of technology application and promote social progress. And the two paths that scholars have proposed are necessary and parallel due to the function of legal. For the former, this research pointed out the inadequacies of the "stage division theory" and proposed a new classification based on "Regulation on Administration of Safety of Agricultural Genetically Modified Organisms" and its corresponding liabilities. For the latter, this research first explained the problem of civil liability through survey data and case study in many aspects. Compared with previous scholars who simply emphasized government remedy, this study points out that socialized remedy should be emphasized, and clarifies the connotation and extension of socialized 
remedy that applied to damage caused by genetic pollution. This research also proposes from the perspective of legislative pattern that the current legislation on damage caused by genetic pollution in China is a single legislative pattern, which should be transformed into a unified comprehensive legislative pattern. In sum, this research elaborated on the current problems and countermeasures of legal remedies for damage caused by genetic pollution from three aspects and put forward innovative viewpoints.

\section{Conflicts of Interest}

The author declares no conflicts of interest regarding the publication of this paper.

\section{References}

Chen, X. (2007). The Risk Society and the Genetically Modified Food Disputes in the United States. Journal of Reading, 2, 3.

Chen, Y. Y. (2015). Research on the Legal Issues Concerning the Coexistence of GM and Non-GM Crops in the EU. German Studies, 1, 56.

Du, Z. M. (2014). Preliminary Discussion on the Compensation System for Genetically Modified Organisms. Journal of Ecological Economics, 12, 18-21.

Jia, A. L. (2011). Research on the Socialization System of Environmental Infringement Damage Compensation (pp. 4). Beijing: Intellectual Property Publishing House.

Kariyawasam, K. (2010). Legal Liability, Intellectual Property and Genetically Modified Crops: Their Impact on World Agriculture. Washington International Law Journal, 3, 3.

Koch, B. A., \& Koziol, H. (2002). Compensation for Personal Injury in a Comparative Perspective (pp. 71). New York: Springer Press.

Lin, C. L. (2014). Research on Liability and Compensation of Transboundary Damages (pp. 94). Beijing: China University of Political Science and Law Press.

Liu, C. (2012). Issues and Logic: An Empirical Study on Environmental Tort Remedy Mechanism (pp. 27). Beijing: Law Press China.

Lv, M. X. (2021). Research on the Convergence of Multiple Relief Mechanisms for Ecological Environmental Damage (pp. 15). Beijing: Comparative Law Research.

Markesinis, B. S. \& Unberath, H. (2002). The German Law of Torts (pp. 143). New York, NK: Hart Publishing.

Miles, L. S., Rivkin, L. R., Johnson, M. T. J., Munshi-South, J., \& Verrelli, B. C. (2019). Gene Flow and Genetic Drift in Urban Environments. Molecular Ecology, 28, 4138-4151. https://doi.org/10.1111/mec.15221

Que, Z. (2015). The Right of Claim for Victims of Genetic Pollution. Chinese Journal of Law, 6, 34

Sun, W. L. (2011). Research on the Economic Impact of Commercialized Planting of Transgenic Insect-Resistant Corn in My Country (pp. 99). Beijing: Economic Science Press.

Tapper, R., Mackenzie, R., Werksman, J., Burhenne-Guilmin, F., \& Kummer, K. (2003). An Explanatory Guide to the Cartagena Protocol on Biosafety. Montreal: Convention on Biological Diversity Secretariat Press.

https://doi.org/10.2305/IUCN.CH.2003.EPLP.46.en 
von Bar, C., Clive, E., \& Schulte-Nölke, H. (2009). Principles, Definitions and Model Rules of European Private Law (pp. 217). Munich: Sellier European Law Publishers. https://doi.org/10.1515/9783866537279

Wang, K. (2016). The Tort Law Meaning of Genetic Pollution. Lanzhou Academic Journal, 12, 103-109.

Wang, M. Y. (2010). On the Law for GMO Safety (pp. 171). Beijing: Peking University Press.

Wang, Z. J. (2009) Civil Law Thinking: The Basic Theoretical System of Claim Right (pp. 55). Beijing: Peking University Press.

Xin, S. (2015). Limits of Civil Remedies for Environmental Damage (pp. 76). Beijing: China University of Political Science and Law Press.

Yang, L. X. (2014). Tort Law (pp. 169). Beijing: People's Court Press.

Zaid, H. G., Hughes, E., \& Porceddu, F. (2001). Glossary of Biotechnology for Food and Agriculture-A Revised and Augmented Edition of the Glossary of Biotechnology and Genetic Engineering (pp. 132). Rome: Food and Agriculture Organization of the United Nation Press.

Zhou, K., \& Yang, Z. J. (2003). On the Comprehensive Coordinating Mechanism for Compensation of Environmental Tort Damage. Chinese Law Review, 6, 47.

Zou, X. (2005). On the Content and System of Environmental Tort Relief System. Journal of Guangzhou University, 9, 43. 